Pumleian Pectures orr ENDOCARDITIS. $\mathbf{B Y}$

Sir THOMAS HORDER, BT., K.C.V.O., M.D., PHYSICIAN TO ST. BARTHOLOMEW'S HOSPITAL.

\section{LECTURE I.*}

MY first and pleasing duty is to thank you, Sir, and the Censors of the College, for the honour of my appointment. to the post of Lumleian lecturer. The gratification which $I$ feel is tempered by humility when $I$ recollect the long line of distinguished Fellows who have held this lectureship, a line which includes the illustrious name of Harvey. A nan of my temperament must needs be appalled by such knowledge, and though my mind is thrilled by the thought that the subject which I have chosen for these lectures is not distinctly related to matters which the greatest of our Fellows illumined by the light of his genius, I tremble at another thought-my incapacity to prove myself worthy of your choice. I shall be satisfied if a few of my audience, generously disposed, may feel helped by reconsideration of old facts by a frank effort to discriminate between what we do and what we do not know, and by the exercise of some care in suggesting how the present gaps in our knowledge may perhaps be filled, whether by clinical observations or by laboratory research. I shall resist the vanity of trying to say all that can bo said on so large a subject, rather contenting myself by selecting certain features which overlap with my personal experience and reflections.

\section{Carditrs.}

It may be advanced that in these days, when more exact knowledge of the inflammatory changes taking place in the heart as the result of rheumatic infection has led us to the realization that the lesion produced is a pancarditis rather than an endo-, peri-, or myo-carditis, the subject of endocarditis has become one of secondary importance. But given this concept of the effect of the rheumatic virus upon the heart, there has arisen, pari passu with its recognition, a growing interest in another type of heart infection in which, as is generally admitted, the brunt of the invasion and of the interaction between the infecting agent and the tissues certainly comes upon the endocardium-I refer to that group of infections which is for the nonce termed " bacteriảl." Of the growing importance of this type of endocarditis, which, but for the objection of adding one -more name to a nomenclature already overburdened, might justly be called, in contradistinction to the iheumatic type, "endocarditis vera," we are all fully aware. I shall ask no indulgence for making it the main purpose of these lectures, nor for bearing it constantly in mind when dealing with other types of endocarditis, with one and all of which it has important relations.

I know of no classification of cases of endocarditis which is scientific, and therefore none that is helpful. Nor do I propose to offer one. If it be true that to have overcome the desire to classify is to have attained a little wisdom, then in this matter I have attained a little. A mero recital of the known infecting agents causing a morbid condition is not a classification, and in the case of endocarditis such a recital must perforce at present find the cause of the majority of cases lacking. I propose to pioceed without a classification. I shall deal first with endocarditis as it results from rheumatic and syphilitic infection; I shall then consider the influence upon the endocardium of certain factors which are not, so far as we can judge, microbic; I shall follow this by a statement of our present knowledge of so-called " bacterial " infections; and I shall conclude by considerations of pathogenesis, prognosis, and treatment.

It was in the course of his Lumleian Iectures in the * Delivered before the Royal College of Physicians, London, on March 23rd. year 1894 that Sturges preached the doctrine of rheumatio carditis. Sturges's subject was "Heart inflammation in children," and ho laid emphasis upon the fact that rheumatic heart affections in children were almost always both endocardial and pericardial. Although he noted the frequency with which the myocaidium was also involved, he thought this occurred as the result of the pericardium having become adherent. This idea was probably a survival of the teaching current before this time, and indeed still prevalent at the time of Sturges's lectures. In Fagge and Pye-Smith's excellent textbook, in the edition appearing three years prior to Sturges's reference, occur the words: " there is no true carditis as there is no true inflammation of the brain. The inflammations of the heart do not directly concern the musclo but the covering and the lining membranes." When this was written careful histological examination of the myocardium in rheumatism had not been undertaken, and, I might add, encephalitis was not prevalent.

It is significant of the slowness with which ideas, however lucidly stated and however logically supported, gain permanent and practical acceptance in medicine that the doctrine so ably advanced by Sturges thirty-two years ago still requires; and receives, reiteration to-day. The growing conviction of clinicians that the heart was seriously involved as a whole, and from the first, in most severe cases of acute rheumatism, coincided with more critical investigation into the state of the heart wall in fatal cases; the discovery by Aschoff of the nodes which bear his name, and the confirmation of these and other changes by many histologists, put this conception of the unity of the cardiac inflammation in this disease upon a firm basis.

Frequency of Carditis in Rheumatism.

Norman Moore, the Lumleian lecturer in 1909, when treating of "Rheumatic fever and valvular disease," advanced the view that the endocarditis of acute rheumatism was the "central condition in the disease." According to Norman Moore, "endocarditis is always" present" in acute rheumatism. "The conclusion to which I wish to attain," he says, "is that every case of rheumatic fever, whether the pains in the joints are slight or severe, is a case of endocarditis, and that the condition of the endocardium is not to be regarded as a frequent complication but as the essential and invariable feature of the disease." Again, "If no evidence of endocarditis is to be found throughout an illness of which a symptom is arthritic pain, then that illness is not rheumatic fever, and the arthritis has some other cause.." According to this view, the various peripheral expressions of the rheumatic infection, such as arthritis, the cerebral symptoms, the lesions in the skin and subcutaneous tissues, etc., aro secondary to the heart affection. Whether he considered the mechanism by which these peripheral symptoms arose to be by a process of embolism or no Norman Moore dift not say, but quite recently Krogius has taken this view, considering the symptoms both in acute rheumatism and in gonorrhoeal rheumatism to be metastatic in nature. The alternative conception, of a virus which invades the blood stream and exercises a special affinity for heart muscle, serous membrane, subcutaneous tissue, skin, and certain parts of theibrain, so that more or fewer of these structures are involved structurally and functionally at the same time, seems rather more probable in the case of acute rheumatism.

Be the mechanism of the infection what it may, we have become satisfied concerning two points in relation to heart affections incident upon acute rheumatism: (1) that there is involvement of the heart in so great a proportion of the cases that it is wise to assume that it may bo involved in all, and this even in the absence of any direct evidence by physical signs; (2) that the inflammation, especially in children, is of the nature of a carditis.

Carey Coombs complains that the subject of rheumatic heart disease is still divided up in even the most recent textbooks under all sorts of headings, and is thereforo only dealt with "in scraps" rather than as an entity possessing a specific cause and presenting a clear clinical and pathological picture. This complaint seems reasonable, and the great importance of the matter justifies the 
strenuous and repeated efforts of this author, as also those of Poynton, an earlier worker along similar lines, to get recognition of the facts as we now know them.

Of the other relations existing between acute rheumatism and endocarditis there is little or nothing to add to the facts as established many years ago. It is a little humiliating, for example, to read again the conclusions drawn by Church just forty rears ago from his examination of 700 cases of the disease, an analysis which is still quoted in the manuals. True, his estimate that only onehalf of the patients affected had some heart affection in their first attack has been considered too low, as seen by my reference to the views of his colleague Norman Moore; but Church's other conclusions have received confirmation down to the present day. For example, he said that the heart, when affected, is usually implicated during the first week of the attack; that the liability to cardiac involvement diminished with age; that no system of treatment, whether by drugs or otherwise, had until then been shown to influence the tendency to endocarditis in acute rheumatism; that relief from pain and fever occurred four or five days sooner in patients treated by salicylates than in those not so treated. It is doubtful if an analysis of the last 700 consecutive cases of acute rheumatism at the same hospital would lead to any different conclusions. Some things, however, which mere statisties could not convey, would, I think, strike the thoughtful investigator, if he took the trouble to study the individual records rather than merely to catalogue the main results.

Growing Infrequency of Rheumatic Fever.

There seems little doubt that cases of severe acute endocarditis during the first attack of the disease are less common than formerly. Further, and perhaps explaining the fact, rheumatic fever in the severe form which was so common even twenty-five years ago is not at all a common disease to-day. Is it not rather uncommon to see a young man, either in hospital or in private practice, presenting the picture of severe rheumatic fever? Yct such cases were an almost daily experience a generation ago. The hypcrpyrexial form of the disease, and cases in which cerebral symptoms were a striking feature, seem entirely to have disappeared. Church, in the analysis just quoted, refers to the fact that already both pericarditis and lung complications had even at that time. become much less frequent, and he adds with caution that it remained to be proved whether this was due to salicylate trcatment or to other causes. After forty years I fear that we must add that we still do not know. May it not have been even then due to some change in the interaction between the virus and the tissues resulting from a change in the virulence of the infecting agent; or to some change in the resistance of the tissues infected? And may not the continued tendency, since Church's analysis was made, for pericarditis, and especially pericarditis with liquid effusion, to become less common, together with the lessened severity. of the cases of acute endocarditis, and of rheumatic fever generally, be expressions of one or both of these same changes?

Following the line of thought introduced by Swift, who refers to two distinct types of response on the part of the tissues to infection by rheumatic fever-the proliferative and the exudative-we should say that the facts just mentioned suggest that exudative changes have become less common, whereas proliferative changes have remained as frequent as before, or have perhaps tended to increase in frequency. I shall refer again later to the relative infrequency of a first attack of acute rheumatic endocarditis in young adults. The possibility of a more complete resolution taking place in a valvulitis at this age, provided no further infection takes place, than in children, in whom the valve cusps are exceedingly thin and delicate, must not be overlooked.

But with this change in the character of the disease wo call acute rheumatism or rheumatic fever, so that its more severe forms and the coincident forms of acute endocarditis and pericardial effusion have become much less common, there has probably occurred an increased frequency of the surhacute and chronic forms of the infection, together with subacute and chronic endocarditis. I have not the benefit of a large experience at a children's hospital, yet I gather that this statement applies equally to children as to adults. It is constantly noted by those who see many ill children that rheumatic heart disease frequently arises in the absence of arthritic signs or indeed of any signs other than those indicative of the carditis. Although this fact was well known to physicians forty years ago, the number of cases of rheumatic heart disease found in children. who present no other feature seems now to bear a larger percentage to the whole than formerly.

\section{Residual Valve Changes.}

Let me turn now to a consideration of the types of endocardial lesions which result from rheumatic infection, whether acute, subacute, or chronic. In the first place, let me trace the course of a mitral endocarditis set up during an attack of rheumatic fever as closely as the known facts will allow. Since we must regard the inflammation as being essentially a valvulitis-a point emphasized by Swift in his recent studies-it is difficult to see how complete resolution can take place in so delicate a structure once it has been inflamed in the particular manner we know to. be characteristic of rheumatism. It is probable, therefore, that few if any cases escapo some degree of resultant injury. It is also probable that the conservative estimates of the earlier observers, such as Church, relative to the frequency of involvement of the heart valves in rheumatism, and also of the proportion of complete recoveries, are explained by the fact that the estimates were made at too short a period of observation after the attack. It was known that the systolic bruit so frequently present during the attack not infrequently disappeared for a time, and then reappeared; but it is likely that many cases, uid especially hospital cases-upon which; almost entirely; statisties are based-were registered as being frce from valve mischief during this rery interval when there were no signs of heart disease. Kemp, as the result of a careful analysis of cases of acute rheumatism in the Radcliffe Infirmary, concludes that these older estimates of the incidence of heart affections, and of subsequent damage, were correct. He also concludes that much that was termed endocarditis in acute rheumatism was really myocarditis, and largely recoverable.

What were the recognized results of the valvulitis caused by acute rheumatism other than the hypothetical recoveries? They were three. (1) Cicatrization takes place, leaving the valve cusps deformed and shrunken, but eventually settling down into permanent shape and remaining so for a long time, it may be many years, until somo other factors come into play to disturb the compensating mechanism in the heart. To this condition the term " mitral incompetence" was given. (2) Further and frequent attacks of rheumatic infection may cnhance the damage and increase the valvular defect. The resultant state of the mitral orifice imposes more difficulty upon the circulation, embarrassed further by associated changes iti the nural endocardium, in the myocardium, and perhaps also in the pericardium, attendant upon the repeated invasions of the virus. The net result of this recurring type of acute rheumatism was the production of what was termed " doublo mitral disease." (3) The third alternativo sequel was the gradual, or rarely the rapid, transition of the case into one of the ulcerating type of endocarditis. Of this sequence more anon.

What was the recognized result upon the mitral valvo of rheumatic infection with more insidious and more chronic symptoms-“" growing pains," mild chorea, myalgias, and various fibrositic manifestations? Although it was believed that many of the cases in this group might develop mitral incompetence with or without stenosis, there was a general belief that the net result was likely to bo the production of mitral stenosis, with little or no regurgit tation. I speak here of tendencies and of average results merely, not of absolute or universal findings. The more purely regurgitant a mitral lesion was found to be the more likely was it that the patient had had an acute attack of rheumatism and one attack only, or, if more than one attack, then with intervals of some years between the attacks. The more purely stenotic the mitral lesion wits found to be, the more likely was it that the patient had 
never had an attack of acute rheumatism, but had had some mild rheumatic manifestations of the chronic kind just mentioned, or gave no history of any rheumatism at all. Looked at from another angle, the type case of mitral incompetence was an adult man who had had a severe but single attack of acute rheumatism in his teens. The type case of double mitral disease was a child or young adult who owed the defect to repeated attacks of rheumatism, largely subacute, and who had considerable myocardial damage in addition. The type case of mitral stenosis was a middle-aged woman, who rarely gave a history of acute rheumatism, and often gave no history of rheumatism at all.

How do these views compare with current ideas as to the resultant valve changes following rheumatic infection? There has been of late years a tendency to consider mitral incompetence a very uncommon sequel to acute rheumatism; indeed, many cardiologists of the present day have discarded the term altogether, or use it only to signify patency of the mitral orifice resulting from cardiac dilatation, temporary or permanent. When faced with a patient who presents signs of what others would term cardiac hypertrophy with a blowing systolic bruit transmitted to the axilla and a diastolic interval free from both bruit and thrill, they explain the state of affairs by postulating a diseased myocardium and a dilated mitral ring; and when dilatation of the heart arrives in such a case they read this to be due to failure of the myocardium originally and permanently damaged by rheumatism rather than due to inability of the hypertrophied ventricle to compensate further for the regurgitation. Others wander still further from the old conception, and, feeling so cerain that the end-result of rheumatic mitral valvulitis is more or less of mitral stenosis, they actually apply this latter term to cases presenting the signs just mentioned. So the apparent anomaly arises, that of two physicians who examine the same case, one will label it " mitral incompetence "-and the other " mitral stenosis." All this is much to the confusion of the student's mind. Without, as ret, the help of proper figures to guide me, I think it is true to say that post-mortem experience favours the view that mitral incompetence due to old rheumatic endocarditis is much less common to-day than formerly.

It is not so very important that such a paradox arises as it is that the circumstance denotes very definitely a changed conception in the rheumatic process. The change is far-reaching in its effect upon our attitude towards post-rheunatic hearts; it is only as yet partly reflected in the textbooks and in the routine teaching of the schools. It is, I think, of more than academic interest to inquire if this change be due to more careful and more prolonged observations carried out upon hearts affectec' by rheumatism or to an actual change in the material observed. That our predecessors were not less skilled than we are with their hands and ears scarcely admits of doubt; and certainly they gave as much time to thought on all these matters. Moreover, be it noted, the particular point is not one upon which either $x$ rays or instrumental methods have thrown much light. It is, however, possible that the opportunity for prolonged observations upon large numbers of cases of heart disease has been greater during the post-war period.

$I$ am as yet uncertain which of the two explanations I have offered for this change of attitude is the correct one, or whether it be each explanation in part. Auricular fibrillation has been the subject of so much attention of late years, and is so intimately bound up with heart failure in mitral stenosis, that there is possibly an added factor hero in concentrating the mind upon this particular condition. Put briefly, the changed conception resolves itself into this-that very much of tho life-history of the rleumatic heart may be expressed by the term "chronic rheumatic valvulitis." There certainly seems much reason in disallowing that the progressive sclerosis which goes on in the mitral cusps and adjacent endocardium, up to the production of the " button-hole" mitral orifice, is merely a slow residual contraction after an initial injury. That some chronic and persistent irritant is still at work through long periods of time seems certain. But is that irritant the rheumatic virus?
The Problem of Mitral Stenosis.

The occurrence of "pure mitral stenosis" in women who give no history of any illness prior to the development of cardiac symptoms has always been a puzzling fact, and remains so to-day. An analysis of the last 100 cases of pure mitral stenosis admitted to St. Bartholomew's Hospital shows that 76 were females and 24 were males. In 63 out of the 100 cases thele was no history of acute rheumatism, and in 36 out of the 100 cases there was no history of rheumatism or of any allied condition. Of these 36 cases, 27 were women and 9 were men. In a careful analysis of 50 cases of mitral stenosis in soldiers Cotton found a history of acute rheumatism in 22 only. French observers have considered that the condition is a congenital one-that is to say, that it begins as a congenital defect, and that this increases as time goes on. Dieulafoy, commenting upon the frequency of, and the unique features presented by, this form of ralvular disease, says, "It is sometimes associated with congenital malformations" (but he does not cite instances of this). "It is independent of rheumatism and the other causes which usually give rise to endocarditis.- This stenosis is associated sometimes with chlorosis." But we in Great Britain do not seem to have found this association any more than wo have found Virchow's hypoplasia of the aorta in this connexion. There has been an effort made by other French observers to associate mitral stenosis with tuberculosis, not so much directly as indirectly, through tuberculous toxins. But this riew, again, lacks confirmation. Poynton drew attention to the constancy with which renal sclerosis was found post mortem in association with these cases of advanced mitral stenosis, and it is interesting to reflect that it is in the same sex, and about the same age, that another musterious sclerosing lesion appears in type form -namely, the so-called " contracting white kidney." Until wo know more of the specific cause of rheumatism we do not seem likely to get nearer to the solution of the problem of this sperial form of mitral scleresis. At present it is impossible either to assert or deny that these cases aro the result of the specific action of the rheumatic virus. The fact that the specific histological lesion of rheumatism is not found in them certainly must not be taken as excluding the possibility of their being rheumatic, for tho chronicity of the process, and the fibroid nature of the changes in the valve segments, would, by analogy with other chronic infections, explain this fact. We do not (readily) find gummatous formations in parasyphilitic diseases, nor tubercles in fibroid types of tuberculosis. Moreover, it is not easy always to demonstrate Aschoff's nodes in some cases of carditis in which, on all other grounds, we have no reasonable doubt that the infection is rheumatic. Whatever the etiology of mitral stenosis in its extreme form in adults may be, it seems certain that the proportionate incidence of chronic sclerosing endocarditis is greater than it formerly was. It is tempting to associate this fact with that other fact to which $I$ have referred-the decline in the incidence of severe acuto rheumatism and a relative increase in mild and recurring cases.

Of the endocarditis occurring in scarlet fever I will only say this-that there seems to be a proportionately greater tendency for aortic involvement than in the case of acute rheumatism, a point to which I shall refer again.

Syphilis of the Fixpocardium.

The affections of the endocardium due to syphilis are probably less difficult to define than in the case of rheumatism. We know that the part most of ten affected is that of the aortic cusps, and we also know that such affection is in most cases part of an aortitis. Syphilitic disease of the aortic cusps leaves theso delicate structures fibrosed and contracted, leading to aortic incompetence and its various sequelac. Rheumatism affects the mitral much more often than the aortic cusps, and probably affects tho aortic cusps alone quite rarely. The converse is the case with syphilis. It is generally held that the mitral cusps are not affected at all by syphilis, but $I$ have been struck by the not infrequent presence of $a$ well marked apical systolic bruit in cases of parasyphilitic disease of the central nerrous system, and in the absence of any history of 
rheumatism. The byuit has been musical in character in some cases-a feature which makes it unlikely that the murmur has been due to mere dilatation of the mitral ring. I am not here referring to cases in which aortic disease is present, and in which, therefore, there might be secondary changes at the mitral orifice.

We owe to Warthin a very complete investigation into the changes induced in the heart and aorta by syphilis. Warthin's studies make it clear that these changes are both diffuse and focal, and we eannot buit be struck by the resemblance in many points between the mode of attack of syphilis and of rbeumatism. In both infections there are produced proliferative lesions, largely perivascular in nature, with nodal structures which are recognizable histologically. There is some not distant resemblance between these nodal lesions in the two diseases, so that it is a little strange that the likeness between the Asehoff bodies in rheumatism and the small gummata in syphilis of the heart has not led observers to consider if the virus of acute rheumatism may not be spirochaetal in nature. Warthin and others have pointed out that the Treponema pallidum is sometimes demonstrated in large numbers in the myocardium, even when there are none to be found elsewhere in the body. So far as the endocardium is concerned the typical lesion of syphilis is undoubtedly a mesaortitis affecting chiefly the base of the aorta, which includes the sinuses of Valsalva, the roots of the aortic cusps, and the part of the aorta just above these structures. No doubt in many instances the process includes a true aortic valvulitis. The disease is prone to be very latent, so that our evidence of its actual incidence, in terms of frequency, can only be assessed indirectly. The sources of this indirect evidence are three. (1) Patients occasionally come under observation with symptoms which render a diagnosis of syphilis of the aortic ring extremely probable, and they respond well to antisyphilitic treatment. I shall return to these later. (2) Aortic incompetence in men about the age of 40, who give no history of acute rheumatism, or of any other infective process likely to cause endocarditis, and whose blood gives a positive complement fixation test for syphilis, is quite common. We seem justified in regarding these cases as residual after old syphilitic disease of the aortic cusps, or indeed as being still the subjects of aortic syphilis. (3) In the post-mortem room wo frequently come across undoubted evidence of syphilitic disease of this region of the aorta which has not been suspected during life. This may be because death has been sudden or because the actual damage to the aortic cusps has not been so severe or so prolonged as to lead to symptoms. The extreme latency which is so marked a feature in syphilitic disease of the aorta was strikingly illustrated in the case of a policeman admitted to St. Bartholomew's Hospital.

His age was 32 year's. His history was to the effect that whilst assisting a fellow constable to lift a corpse down a flight of stairs his companion, who went before, slipped on a step and fell. The patient, in order to save himself from falling also, fell. The patient, in order to save himself from falling also,
leant back heavily, still holding on to the dead body. At the moment that he did this he felt a sharp pain in his chest and became faint. He was assisted downstairs and to the open air, sat down, and soon felt better. However, he was sent home, and, still feeling queer, he went to bed. His wife, who was out at the time of his arrival, returned and brought him some tea. As he was taking this he saw his wife looking about the bedroom as whough searching for something, and on his inquiring what it was, "I was looking for the cat," she replied. She then explained to him that she could hear the cat purring. However, no cat could be found, and the woman discovered to her surprise, on approaching the bed more closely, that the purr proceeded from her husband's chest. The pain from which the patient at first suffered had gone completely in three or four days; he was kept in bed for ten days, and then sent by ambulance to hospital. When seen, the bruit was still very loud, and could be heard distinctly by leaning over the bed, it being not necessary for the observer's head to touch the chest wall. The murmur was highly musical in character and was diastolic in time. There was no evidence of cardiac hypertroply, but there were the usual arterial evidence of cardiac hypertrophy, but there were he usual arterial
signs of aortic regurgitation. $A$ fairly marked anaemia was present and a "triple plus" Wassermann reaction. There was a history of syphilitic infection ten years previously. The patient improved rapidly under treatment by potassium iodide and mercury, and left the hospital well, but with the signs of aortic regurgitation. There can scarcely be much doubt that this was a case of rupture of an aortic cusp already the site of a syphilitic valvulitis.

All this indirect evidence, taken together, makes it certain that syphilitic aortitis, with aortic valvulitis, is a not uncommon disease. It is obviously very important that we should bear this fact in mind in our practice, and be prepared to suspect the disease, even though, as I shall now proceed to show, our means of diagnosing it with certainty are slender. If we wait until gross structural changes are produced in the aortic cusps we wait too long. It is to be doubted whether, in syphilis, as in acute rheumatism, complete resolution can ever take place onte valvulitis has been present. But by checking, or by stopping altogether, the process of active infiltration and proliferation in the valve cusps, we can lessen the residual damage in these structures, and thus prolong considerably the period of relative cardiac suffieiency which every case of aortic incompetence can only at best enjoy. No doubt a part of this increased freedom from undesirable sequelae is due here, as it is in rheumatism in similar circumstances, to the fact that the myocardium has been protected from gross damage.

Age-Incidence of Aortic Syphilis,

An important question arises: At about what interval after the primary infection does syphilitic disease of the aorta begin? At about what age shall we begin to consider the possible presence of the disease? In treating quite recently of a series of cases of cardiac syphilis Carey Coombs computes that the period between infection' 'and the onset of the symptoms was over twenty years; he gives the average age of his patients as 53 . Coombs does not distinguish between the cases showing evidence of aortic disease and those whose main defect happened to be myocardial, and it may perhaps be assumed that such distinction would have affected these figures. As the result of a still larger number of cases studied by him, Strickland Goodall has recently put the period elapsing between the primary infection and the appearance of symptoms even higher than this. Although I am unable to give statistics, I am led to the view from my own experience that these figures give no true expression of the early cases of the disease. It is notoriously difficult to differentiate between the fibrotic residues of old inflammation and the lesions of still active disease; no more common problem arises in the post-mortem room than the proper interpretation of the changes frequently seen in the aorta. And no less difficulty arises in regard to the interpretation of symptoms during life: are they due to active disease or to atheromatous changes in the production of which syphilis is only one causative factor? If we follow the view that smouldering infection still remains in all cases in which there is to be obtained a positive complement fixation test, this makes it more, and not less, likely that the first invasion of the tissues by the Treponema pallidum takes place much earlier than signs or even symptoms show themselves.

Is it not probable that the known facts in regard to that other distinctive and equally common syphilitic arterial disease, cerebral arteritis, give us some guide in this connexion? Unless we have some reason for taking' a different view it is at least likely that the time of incirlence in the course of syphilis of arteritis in the branches of the circle of Willis approximates to the time of incidence of syphilis of the aorta and the aortic cusps. And the former we have fairly good evidence for placing at from five to ten years after the primary infection. The difference in the age incidence when calculated from a large sories of cases would be explained by the fact that syphilis of the cerebral arteries can scarcely remain long without symptoms, whereas srphilis of the aorta can, and frequently does. Perhaps this matter may be stated most clearly by postulating two somewhat different types of lesion produced by syphilis in the acrta, as there are two somewhat different types of lesion in the central nervous system. There is an earlier lesion of the gummatous kind, largely proliferative in character and possessed of focal lesions in a high degree, and a later type of lesion, largely fibrotic in its features, to which the term "parasyphilitic" may be not inappropriately applied. If this conception be admissible then the apparent discrepancy to which .I have referred would be explained. So also would be explained, and rendered again analogous, the known lack of effective response to antisyphilitic treatment in cases of syphilitic aortitis when once the signs of aortic 
incompetence are present. No doubt both typès of lesign may bo present at the same time-a fact which accounts in part for the great difficulty often experienced in the interpretation of post-mortem findings. If this view be substantially correct it becomes a still more urgent matter to track down the early cases by all means in our power. We must look for these cases in men (by preference) who are between the ages of 25 and 40 .

\section{Symptoms of Aortic SyphiuIs.}

The main-and in perhaps most of the cases the onlysymptom is pain, anginoid in character, situated in the jegion of the sternum rather than in the region of the precordium, with a zone of reference or spread less extensive than is usual in angina pectoris. The pain is usually induced by, or increased with, effort, but this feature is not constant. Shortness of breath and the effort syndrome are sometimes present, but when this is so it is probable, from our general knowledge of these symptoms, that there is myocardial disease in addition to, or rather than, artitis. There may be complaint of more general symptoms, such as slackness and vague dyspeptic symptoms, and the patient may be anaemic. But since these latter symptoms are common to so many diseases it remains that it is the pain, and the pain alone, which arouses our suspicions in most of the cases.

As regards physical signs, these are absent or are equivocal. Lack of clearness in the aortic socond sound, whether directly over the valve or at any point where the aortic second sound is listened to critically-and this should include the region just above the xiphisternum-is rery skppicious. A ringing character to this sound, in the absence of high arterial tension, is perhaps equally signifieant. More change than one of these-to wit, a definite diastolic bruit-probably means that the ralvulitis is not carly, and that resolution will not occur completely with treatment. I have only once, in a case of syphilitic aortitis, heard a definite diastolic bruit which disappeared with antisyphilitic treatment. It returned some two rears later, despite continued treatment, and the patient then developed the arterial signs of aortic regurgitation. It is to be inferred that the disease was not detected at a sufficiently early stage to avert cicatricial changes. It is perhaps doubtful if we could ever completely arert some degree of cicatricial changes if a syphilitic valvulitis were ouce established, any more than we can in a rheumatic valvulitis, even though our means of treatment are much more "specific." The disappearance of the bruit and its reappearance later in permanent fashion is very reminiscent of what we know to happen not infrequently in the case of rheumatic fever.

I have never satisfied myself that the disease in its ciuable stage yields demonstrable dilatation of the aorta by physical signs. Nor have I ever got this evidence from o-ray examination, though I understand that Price has met with a different experience. Our French colleagues construct a more elaborate picture of the signs and symptoms of early degrees of aortitis, but I find it difficult to follow them in actual practice. I doubt if at present we can go further than to say that a man below the age of 50, whose arterial tension is not raised, whose blood gives a positive complement fixation for syphilis, and who complains of pain that may reasonably be attributed to the aorta, is probably suffering from syphilitic disease of this structure. If his age be under 40 the diagnosis is less uncertain. Treatment should be carried out promptly and thoroughly, and, since it is held strongly by some high authorities that active syphilitic infection should be presumed so long as the complement fixation test remains positive, here, at least, this doctrine should determine our action, since there is so much to gain if it-be true, and so littlo to lose if it be false. The important points are these: first, that it may be possible to detect and to treat syphilitic aortitis before the aortic cusps are involved; and secondly, that if it be detected and treated while as yet the degree of valvulitis is slight, the resultant Falve damage may be so little, and so unprogressive, iss not to prejudice the patient for an indefinite number of years.

\section{OBSERVATIONS ON THE FRONTAL SINUS. \\ BY}

WILLIAM OLIVER LODGE, M.D., F.R.C.S.ED., D.O.M.S.ENG.

OPHTHALMIC SURGEON, BRADFORD MUNICIPAL GENERAL HOSPITAL, ETC.

Catarreat Inflammation.

IT is during quiet intervals that the diagnosis of the milder forms of recurrent catarrhal inflammation of the frontal sinus presents most difficulty. Deep tenderness may be elicited, but the floor of the sinus is a tender spot in most individuals. Often the nasal chambers appear healthy; transillumination is of no help, and the radiographer makes a negative report. Everything depends on a reliable account of the symptoms. The following case exemplifies this common type.

\section{CASE I.}

A woman, aged 41, complained of intermittent aching and feeling of congestion in the frontal region. During the attacks, which recurred at varying intervals, usually after a cold in the head, and lasted for a tew days, the timbre of the voice was slightly altered. Six months previously, after confinement to bed for a week owing to severe frontal pain on the left side, there was a sudden escape of slimy fluid into the nose, with immediate relief.

Pain was elicited on pressing upwards on the roof of the orbit on both sides. There was a little mucoid sesretion in the nasal vestibule, but none in the middle meatus on either side. Prominent opercula did not permit of the passage of a probe up the fronto-nasal ducts. On radiographic examination the paranasal sinuses were reported normal. 'The patient preferred to await further developments before resorting to any form cf operative investigation or treatment.

The early and continued use of a nasal spray containing menthol, chloretone, etc., in an oily base sometimes wards off an attack. During an attack the introduction of a pledget of cotton-wool moistened with cocaine and adrenaline solution beneath the middle turbinal may give relief. Resection of the anterior portion of the middle turbinated bone, with or without probing and dilatation of the duct, yields more consistently satisfactory results; but to persuade patients during a quiet interval to submit to operation would in most cases entail an unjustifiable promise of cure without risk.

\section{MUCOCELE.}

Mucocele is less frequent in the frontal than in other accessory sinuses. The first complaint is generally of pain, or of some visual disturbance, such as epiphora, diplopia, or proptosis. The conditions which would appear to favour the development of mucocele are closure of the outlet, which may be partial or intermittent, and absence of pyogenic organisms. The walls are expanded or a breach is made and an external swelling forms. Pressure over the swelling may cause some of the thick glairy green contents to trickle into the nose. The obstruction may be developmental, but a variety of causes, among them osteoma of the frontal sinus, have been recorded. In the following case, associated with polypoid disease, the walls of the sinus were much expanded but still intact at the time of operation.

\section{CASE II.}

A man, aged 30, complained of a swelling which was becoming increasingly prominent in the right supraorbital region, of nasa obstruction of some year's duration, which was now complete on the right side, of a sense of heaviness about the eyes, and of frontal headache.

The swelling, which was smooth and round, occupied the space between the inner canthus, the superciliary ridge, supraorbital notch, and root of the nose. It was firm to the touch, and merged imperceptibly into the adjacent surfaces. The nasal obstruction was due to polypi, which blocked the right side of the nose was due to polypi, which blockef the right side of the nose completely and obstructed the left side to a minor degree. A skiagram showed spacious paranasal sinuses, the shadows of
which were clear (especially that of the right frontal sinus), which were clear (especially that of the right frontal sinus),
except that there was some degree of "veiling " of the shadow of the right antrum.

opcration.- Under general anaesthesia, administered through Kuhn's tube, a curved incision was made along the inner third of the superior orbital margin and continued downwards to the inferior orbital margin. The lacrymal sac was displaced from its groove, and, commencing just above this point, the from its groove, and, commencing just above this point, the
bone was removed from the outer wall of the nose and inner part of the floor of the sinus. On incising the mucous membrane part of the floor of the sinus. On incising the mucous membrane
the infundibulum was found to be packed with polypi. The sinus itself was filled with greenish viscid fluid of unpleasant 